\title{
I 087 Right and left ventricular morphologic and functional differences between patients with severe idiopathic vs. secondary pulmonary hypertension; insights from cardiovascular MRI Vikas K Rathi*, Srinivas Murali, Madhavi Akkineni, June Yamrozik, Ronald Williams, Diane A Vido, Mark Doyle and Robert WW Biederman
}

Address: Allegheny General Hospital, The Gerald McGinnis Cardiovascular Institute, Pittsburgh, PA, USA

* Corresponding author

from I th Annual SCMR Scientific Sessions

Los Angeles, CA, USA. I-3 February 2008

Published: 22 October 2008

Journal of Cardiovascular Magnetic Resonance 2008, I0(Suppl I):A2 I2 doi:I0.II86/I532-429X-I0-SI-A2 I2

This abstract is available from: http://jcmr-online.com/content/I0/SI/A2I2

(c) 2008 Rathi et al; licensee BioMed Central Ltd.

\section{Introduction}

In pts with long standing pulmonary hypertension (PHTN), RV is the primary organ to withstand the increased pressure which overtime leads to insidious right heart failure. However, the effect of decreased preload due to PHTN and the failing RV on LV function and geometry is unknown. Theoretically, the LV should be spared but clinically it is often noted that, despite a small LV, the perception of a hypertrophied LV with abnormal geometry by $1 \mathrm{D}$ and $2 \mathrm{D}$ techniques is present.

\section{Hypothesis}

In PHTN there will be abnormal LV volumetrics and geometry due to the impaired preload from RV dysfunction and a $3 \mathrm{D}$ evaluation will rectify $1 \mathrm{D}$ and $2 \mathrm{D}$ observations.

\section{Methods}

Pts (32) age $55 \pm 16$ with severe PHTN were divided in two groups: 10 pts with idiopathic PHTN (IPHTN) and 22 with secondary PHTN (SPHTN). All pts underwent cardiac MRI (CMR) measuring 3D RV and LV EDV, ESV, EF, mass, relative wall thickness (RWT) indexed to BSA and TAPSE.

\section{Results}

All pts had severe PHTN $(63 \pm 29 \mathrm{mmHg})$ with no significant difference in PA pressure between IPHTN vs SPHTN $(78 \pm 22.7$ vs $64 \pm 28.5, \mathrm{p}=\mathrm{NS})$. Pts with PHTN had a markedly elevated RVEDVI relative to LVEDVI (108.22 \pm $66.23 \mathrm{ml} / \mathrm{m} 2)$ vs. $(63.33 \pm 20.12 \mathrm{ml} / \mathrm{m} 2)(\mathrm{p}<0.05)$ representing very opposite ends of the normal volume spectrum. RVEDVI was $=2 \mathrm{SD}>$ normal while LVEDVI was $1 \mathrm{SD}<$ normal. Distinguishing IPHTN from SPHTN demonstrated that RVEDVI were much higher $(138 \pm 92.3 \mathrm{ml} /$ $\mathrm{m} 2$ vs $93.2 \pm 43.7 \mathrm{ml} / \mathrm{m} 2, \mathrm{p}=0.06$ ) while there was virtual superimposition of LVEDVI independent of etiology of PHTN $(61 \pm 25 \mathrm{ml} / \mathrm{m} 2$ vs. $64 \pm 17 \mathrm{ml} / \mathrm{m} 2 \mathrm{p}=\mathrm{NS})$. LV geometry revealed normal $1 \mathrm{D}$ septal and posterior wall thickness translating into normal RWT: $0.36 \pm 0.1$ while LVMI was low normal: $55 \pm 17 \mathrm{~g} / \mathrm{m} 2$ (normal: $59 \pm 11$ ). TAPSE positively correlated with $\operatorname{RVEF}(\mathrm{r}=0.6, \mathrm{p}<0.05)$.

\section{Conclusion}

Using 3D CMR, despite the concept that the $\mathrm{LV}$ is smaller and possesses abnormal geometry by $1 \mathrm{D} / 2 \mathrm{D}$ interrogations, 3D LV metrics are entirely normal. Unexpectantly, the LV, despite markedly impaired preload, especially in IPHTN relative to SPHTN, regulates normal volumetrics independent of PHTN etiology. Paradoxically, patients with IPHTN appear to have limited ability to withstand pressure overload as compared to SPHTN, resulting in marked RV dilation while it is known that for the LV the exact opposite is true. 